\title{
The Prevalence of Undetected Vertebral Fracture in Patients with Back Pain by Dual-Energy X-ray Absorptiometry (DXA) of the Lateral Thoracic and Lumbar Spine
}

\author{
Ali Reza Ehsanbakhsh', Hadi Akhbari², Morteza Bahri Iraee ${ }^{3}$, Farokh Sailanian Toosi', \\ Nasrin Khorashadizadeh', Mohammad Reza Rezvani², Ghodratollah Naseh ${ }^{4}$ \\ 'Department of Radiology, Valie-asr Hospital, Birjand University of Medical Sciences, Birjand, Iran \\ ${ }^{2}$ Department of Internal Medicine, Valie-asr Hospital, Birjand University of Medical Sciences, Birjand, Iran \\ ${ }^{3}$ Espetialist of Nuclear Medicine, Birjand Nuclear Medicine Center, Birjand, Iran \\ ${ }^{4}$ Department of Surgery, Imam Reza Hospital, Birjand University of Medical Sciences, Birjand, Iran
}

Study Design: This is a prospective study.

Purpose: This study is conducted to determine the prevalence of unrecognized vertebral fracture (VF) in patients who present with back pain.

Overview of Literature: $\mathrm{VF}$ is often unrecognized, and significantly increases the risk of further fractures. Unfortunately, the patients at a high risk for VF usually do not receive adequate therapy to reduce the fracture risk.

Methods: This is a prospective study of 344 patients who presented with back pain from April 2008 to May 2009. The patients underwent dual-energy X-ray absorptiometry (DXA) evaluation and vertebral fracture assessment from T4 to L4 using a hologic densitometer.

Results: Three hundred forty four of 386 patients who presented with back pain were included. Forty two patients were excluded because of a prior history of VF or the lack of written consent. Most of the patients were female (95.3\%). The mean age of the patients was $58.21 \pm 11.74$ years. According to the World Health Organization definition (based on the Tscore), $13.4 \%$ of the patients had normal lumbar spine bone mineral density (BMD). $27.9 \%$ of them were osteopenic and $58.7 \%$ were osteoporotic. The overall prevalence of $\mathrm{VF}$, as established by lateral vertebral assessment, was 39\% ( $\mathrm{n}=134$ ). Moreover, $62.6 \%(n=84)$ of the patients with VF had more than one fracture and $64.1 \%(n=86)$ of them had Grade 2 or 3 fracture.

Conclusions: We recommend performing not only DXA scanning for BMD evaluation, but also VFA by DXA in old patients with back pain.

Key Words: Osteoporosis, Vertebral fracture, Absorptiometry, Photon

\section{Introduction}

The majority of patients with osteoporotic vertebral frac- ture (VF) remains undetected and only $30 \%$ of them are recognized and diagnosed [1]. These patients not only have a higher risk of further fractures at the spine and other skeletal sites [2-4], but they also bear higher rates of morbidity

Received May 23, 2010; 1st Revised Aug 7, 2010; 2nd Revised Feb 22, 2011; Accepted Feb 22, 2011

Corresponding author: Ali Reza Ehsanbakhsh, MD

Department of Radiology, Valie-asr Hospital, Birjand University of Medical Sciences,

P.O. Box 97179-64151, Birjand, Iran

Tel: +98-5614443001-9, Fax: +98-5614431492, E-mail: a.r.ehsanbakhsh@gmail.com 
and mortality $[5,6]$.

There are some methods for evaluating and detecting VFs and these include plain radiography, computed tomography (CT), magnetic resonance imaging (MRI), nuclear bone scanning and vertebral fracture assessment (VFA) by dualenergy X-ray absorptiometry (DXA).

Plain spine radiography is usually applied to assess VFs [7]. However, it has limitations for the evaluation of VFs, and especially for subtle (Grade 1) fractures with more radiation exposure relative to that of VFA by DXA. The effective radiation dose for a lateral lumbar spine $\mathrm{X}$-ray is about 600 micro-Sievert $(\mu \mathrm{Sv})$ [8]. CT scanning and MRI give excellent image resolution, but they are less available, more expensive and more inconvenient for patients. There is not any gold standard test for the detection of osteoporotic VFs. One of the more reliable and new methods for detecting VFs is VFA and this is usually performed with a semi-quantitative (SQ) method. According to this method, VFs are recognized by a combination of morphometric and visual assessment. The semiquantitative system of Genant et al. [9] is commonly used for grading vertebral deformities (Fig. 1). This methodology has been recently used in many clinical trials and in clinical practice [10-16]. VFA by DXA is a fast, low-dose radiation technique that generates satis- factory quality images to evaluate VFs [15]. The effective radiation dose for VFA is about $3 \mu \mathrm{Sv}$ [8]. By comparison, the typical background radiation at sea level in the United States is about $7 \mu \mathrm{Sv} /$ day [17].

The advantages of using VFA-DXA over the conventional radiographic methods are its minimal radiation exposure and high-speed image acquisition. It also allows combined evaluation of the status of VFs and the bone mass density, and VFA-DXA can be a standard method for evaluating patients with osteoporosis. The disadvantage of VFA-DXA is that the upper thoracic vertebrae (above T7) cannot be adequately evaluated in a substantial number of patients due to poor imaging quality [18]. Moreover, VFA does not show good performance for diagnosing mild (Grade 1) VFs $[19,20]$ or in the presence of scoliosis [15], as well as its poor performance for patients with moderate/severe disk space osteoarthritis [21].

Nonetheless, the ability to view the entire spine in one image without cone beam distortion is an advantage with VFA-DXA [17]. In addition, many studies have shown that VFA-DXA compares favorably with plain spine radiography for making the diagnosis of VFs [15,19-21].

In this study, we aimed to determine the prevalence of undetected VFs in patients with back pain by performing

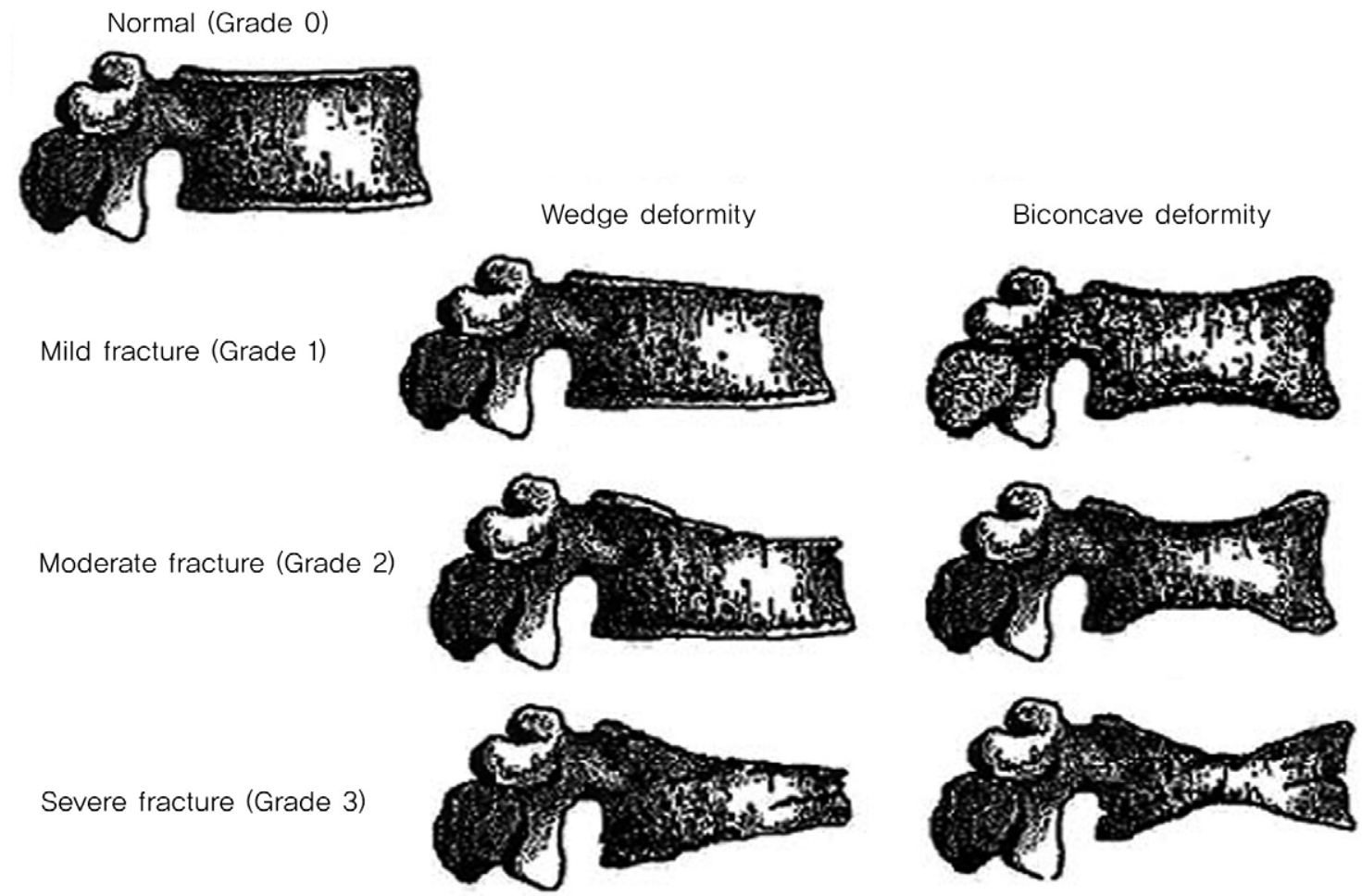

Fig. 1. Schematic diagram of the semiquantitative grading scale for vertebral fractures (from Genant et al. [9]). 


\section{VFA-DXA}

\section{Materials and Methods}

This prospective study was performed on 342 patients who presented with back pain at the Department of Rheumatology of Birjand University of Medical Sciences in Iran from April 2008 to March 2009.

Three hundred eighty six patients were initially referred to our center; however, 42 of them were excluded from the study because of a previous history of VF that was the result of any causes, including malignant or metastatic spinal lesions, post-traumatic deformity, degenerative remodeling, Scheurmann's disease, congenital anomaly, and Pott 's disease $(\mathrm{n}=30)$, as well as those who refused to give consent for entering to the study $(\mathrm{n}=12)$.

Informed consent was obtained from all the enrolled patients. The patients underwent DXA evaluation on their lumbar spine (L1 to L4) and the left hip for bone densitometry at the Sina Imaging Center, Birjand with using a Hologic bone densitometer (Discovery W model, Hologic, New York, NY, USA). Lateral vertebral assessment (LVA) evaluation was also performed on the DXA machine from the T4 to L4 vertebral bodies. We used Genant's SQ methodology for LVA.

Based on Genant's method, the VFs were classified to three grades: Grade 1 or mild (20-25\% loss of the vertebral height), Grade 2 or moderate (25-40\% loss of the vertebral height) and Grade 3 or severe (more than $40 \%$ loss of the vertebral height). All the images were reviewed and reported on by 2 expert radiologists and the results were compared. The radiologists were kept 'blinded' to the identity of the patients and their clinical data. All the data were analyzed by SPSS ver. 15 (SPSS Inc., Chicago, IL, USA). Chi square and logistic regression (multivariate and univariate analyses) tests were used for the statistical analysis and $p$ values less than 0.05 were considered significant.

\section{Results}

Among the 344 patients $95.3 \%(n=328)$ were female and only $4.7 \%(n=16)$ were male. The mean age of the patients was $58.21 \pm 11.74$ years. The youngest was 44 years old and the oldest patient was 79 years old.

Based on the World Health Organization criteria of osteoporosis, $13.4 \%(n=46)$ of the patients had normal lumbar spine bone mineral density (BMD) (T-score, $\geq-1$ ), $27.9 \%(\mathrm{n}=96)$ were osteopenic (T-score, -1.1 to -2.4$)$ and $58.7 \%(\mathrm{n}=202)$ were osteoporotic (T-score, $\leq-2.5)$.

The overall prevalence of VFs recognized by LVA was $39 \%(\mathrm{n}=134)$ and among these VFs, $37.4 \%(\mathrm{n}=50)$ were single VF and $62.6 \%(n=84)$ were more than one VF (multiple VFs). One hundred thirty four of the 344 patients (39\%) had VFs recognized by LVA and 50 patients $(37.4 \%)$ had a single VF and $62.6 \%(n=84)$ had more than one VF (multiple VFs). Similarly, 35.9\% (48/134) of the patients with VF had Grade 1 VF and 64.1\% (86/134) had Grade 2 or $3 \mathrm{VF}$.

Likewise, $56.4 \%(114 / 202)$ of patients with osteoporosis did not show a definite $\mathrm{VF}$ and the remaining $43.6 \%$ $(88 / 202)$ had VFs $(25 \%$ [22/88] showed a single VF and $75 \%$ [66/88] showed multiple VFs). As a result, $10.8 \%$ $(22 / 202)$ of all the patients with osteoporosis exhibited a single VF and $32.7 \%$ (66/202) showed multiple VFs

In addition, $62.5 \%(60 / 96)$ of the patients with osteopenia had no VF and the remaining 37.5\% (36/96) revealed VFs (61\% [22/36] demonstrated a single VF and 39\% [14/36] showed multiple VFs). Hence, $23 \%$ (22/96) of all the patients with osteopenia showed a single VF and $15 \%$ (14/96) showed multiple VFs.

Last, $78 \%(36 / 46)$ of the patients with a normal T-score had no any evidence of VF and the rest of the them $(22 \%$, 10/46) were diagnosed with VFs $(60 \%$ [6/10] had a single VF and 40\% [4/10] had multiple VFs). Thus, 13\% (6/46) of

Table 1. Impact of lumbar spine T-score on the prevalence of vertebral fracture

\begin{tabular}{lcccc}
\hline \hline Lumbar spine T-score & Total (each group) & Single VF & Multiple VFs & Fracture of Grade 2 or 3 \\
\hline Normal $(\geq-1.0)$ & $46(13.4)$ & $6(13.0)$ & $4(8.7)$ & $2(4.3)$ \\
Osteopenic $(-2.4$ to -1.1$)$ & $96(27.9)$ & $22(22.9)$ & $14(14.6)$ & $20(20.8)$ \\
Osteoporosis $(\leq-2.5)$ & $202(58.7)$ & $22(10.9)$ & $66(32.7)$ & $64(31.6)$ \\
Total (all patients) & $344(100)$ & $50(14.5)$ & $84(24.4)$ & $86(25.0)$ \\
\hline
\end{tabular}

Values are presented as number (\%)

VF: Vertebral fracture.

${ }^{a}$ Chi-square $=7.858, p=0.02,{ }^{\text {b) }}$ Chi-square $=23.622, p=0.001,{ }^{\mathrm{c}} \mathrm{Chi}$-square $=18.078, p=0.006$. 
all the patients with a normal T-score showed a single VF and $8.7 \%$ (4/46) showed multiple VFs. The osteoporotic patients (T-score, $\leq 2.5$ ) were significantly more likely to have single and multiple VFs (43.6\%) as compared with that of the patients who were osteopenic (37.5\%) and those patients who had a normal (21.7\%) T-score $(p=0.02)$ (Table 1).

Based on the body mass index (BMI), 13.9\% (48/344) of all the patients were underweight (BMI, $<20 \mathrm{~kg} / \mathrm{m}^{2}$ ), while only $25.5 \%$ (88/344) of the patients were within the normal range of the BMI (BMI, 20 to $\left.25 \mathrm{~kg} / \mathrm{m}^{2}\right), 36.7 \%$ (126/344) were overweight (BMI, 25.1 to $30 \mathrm{~kg} / \mathrm{m}^{2}$ ) and finally $23.9 \%$ $(82 / 344)$ were obese (BMI, $\left.>30 \mathrm{~kg} / \mathrm{m}^{2}\right)$.

In the group of underweight patients (BMI, $<20 \mathrm{~kg} / \mathrm{m}^{2}$ ) multiple VFs were seen more frequently and this was statistically significant $(p=0.002)$ when compared to the other subgroups. These underweight patients were also significantly more at risk for Grade 2 or 3 VFs $(p=0.003)$ (Table 2).

The older patients also showed significantly more multiple VFs as compared to that of the other subgroups ( $p=$ 0.001 ), and the older patients also had more VFs of Grade 2 or $3(p=0.001)$ (Table 3$)$.

In the assessment of the locations of the VFs, $48 \%$ were only in the thoracic spine, $25 \%$ were in the lumbar spine and $27 \%$ of the patients showed VFs in both the thoracic and lumbar spine. The LVA-DXA scans of the patients are shown in Fig. 2.

\section{Discussion}

A global prospective study (the IMPACT study) [22] compared the results of local radiographic reports of more than 2,000 postmenopausal women with osteoporosis from five continents with that of subsequent central readings. This study demonstrated that VFs worldwide were frequently underdiagnosed radiologically, with false-negative rates as high as $30 \%$ despite a strict radiographic protocol that provided an unambiguous VF definition and it minimized the influence of inadequate film quality. It was concluded that the failure was a global problem and this was attributable to either a lack of radiographic detection or use of ambiguous terminology in reports. Therefore, it is very important to use standardized methods for the visual assessment of VFs.

The LVA-DXA can be a standard method for evaluating patients with osteoporosis and VFs. In our study, about 39\% $(134 / 344)$ of the patients presenting with back pain had an unrecognized VF (including single and multiple VFs), of which $62.6 \%$ were multiple and $37.4 \%$ were single VFs that were detected by LVA-DXA.

Table 2. Impact of BMI on the prevalence of vertebral fracture

\begin{tabular}{lcccr}
\hline \hline BMI $\left(\mathrm{kg} / \mathrm{m}^{2}\right)$ & Total (each group) & Single VF & Multiple VFs & Fracture of Grade 2 or 3 \\
\hline Underweight $(<20)$ & $48(13.9)$ & $6(12.5)$ & $22(45.8)$ & $20(41.7)$ \\
Normal $(20-25)$ & $88(25.5)$ & $12(13.6)$ & $22(25.5)$ & $26(29.5)$ \\
Overweight (25.1-30) & $126(36.7)$ & $14(11.1)$ & $24(19.0)$ & $24(19.0)$ \\
Obese (> 30) & $82(23.9)$ & $18(21.9)$ & $16(19.5)$ & $16(19.5)$ \\
Total (all patients) & $344(100)$ & $50(14.5)$ & $84(24.4)$ & $86(25.0)$ \\
\hline
\end{tabular}

Values are presented as number $(\%)$.

BMI: Body mass index, VF: Vertebral fracture.

${ }^{\text {a) }}$ Chi-square $=5.037, p=0.17,{ }^{\text {b) }}$ Chi-square $=20.264, p=0.002,{ }^{\text {c) }}$ Chi-square $=19.703, p=0.003$.

Table 3. Impact of age on the prevalence of vertebral fracture

\begin{tabular}{lcccc}
\hline \hline Age (yr) & Total (each group) & Single VF ${ }^{\text {a) }}$ & Multiple VFs ${ }^{\text {b) }}$ & Fracture of Grade 2 or 3 \\
\hline$<50$ & $98(28.5)$ & $8(8.1)$ & $12(12.2)$ & $14(14.3)$ \\
$50-59$ & $94(27.3)$ & $18(19.1)$ & $16(17.0)$ & $12(12.8)$ \\
$60-69$ & $94(27.3)$ & $16(17.0)$ & $32(34.0)$ & $32(34.0)$ \\
$\geq 70$ & $58(16.9)$ & $8(13.7)$ & $24(24.4)$ & $28(43.3)$ \\
Total (all patients) & $344(100)$ & $50(14.5)$ & $84(24.4)$ & $86(25.0)$ \\
\hline
\end{tabular}

Values are presented as number $(\%)$.

VF: Vertebral fracture.

${ }^{a}$ Chi-square $=5.307, p=0.15,{ }^{\text {b }}$ Chi-square $=33.386, p=0.001,{ }^{c}$ Chi-square $=49.197, p=0.001$. 
Eighty six patients had Grade 2 or Grade 3 VFs, which was $64 \%$ of all the patients with VFs (from 134) and 25\% of all the referred patients (from 344). On the other hand, $36 \%$ of all VFs (14\% of all the patients) were Grade 1 (according to Genent's classification). A similar study that sub-analyzed patients by the grade of the VFs revealed that almost $75 \%$ of the patients had VFs of Grade 2 and Grade 3 , and Grade 1 fracture was seen when the non-osteoporotic etiology for VFs was considered more likely [23], and this emphasizes the importance of Grade 2 or 3 for osteoporotic VFs.

In addition, our patients predominantly had multiple VFs (62.6\%). There was a high prevalence of VFs in our study as compared with that of similar studies. This may be due to higher prevalence of osteoporotic (58.7\%) and osteopenic (27.9\%) patients in our population.

The prevalence of VFs was $20 \%$ (42\% of which were multiple) in the study by Black et al. [4], 18.3\% in the study
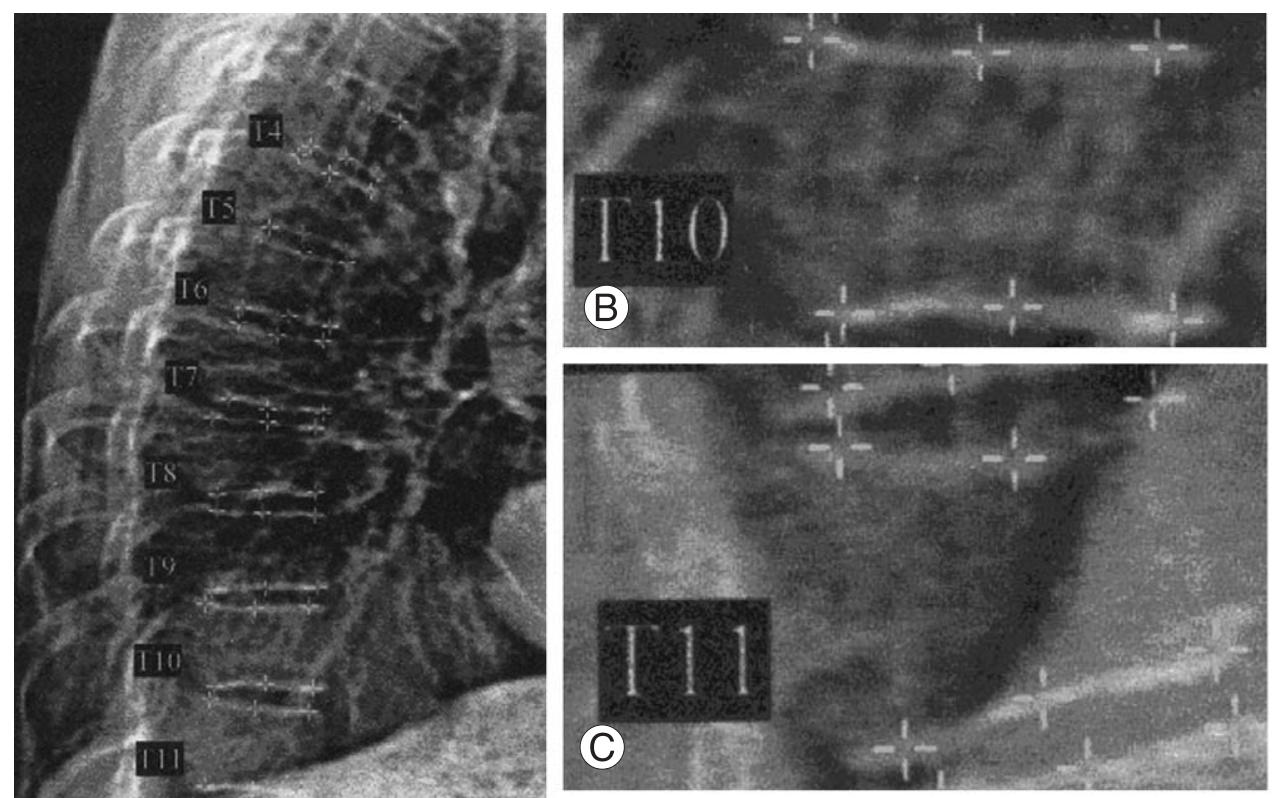

(A)
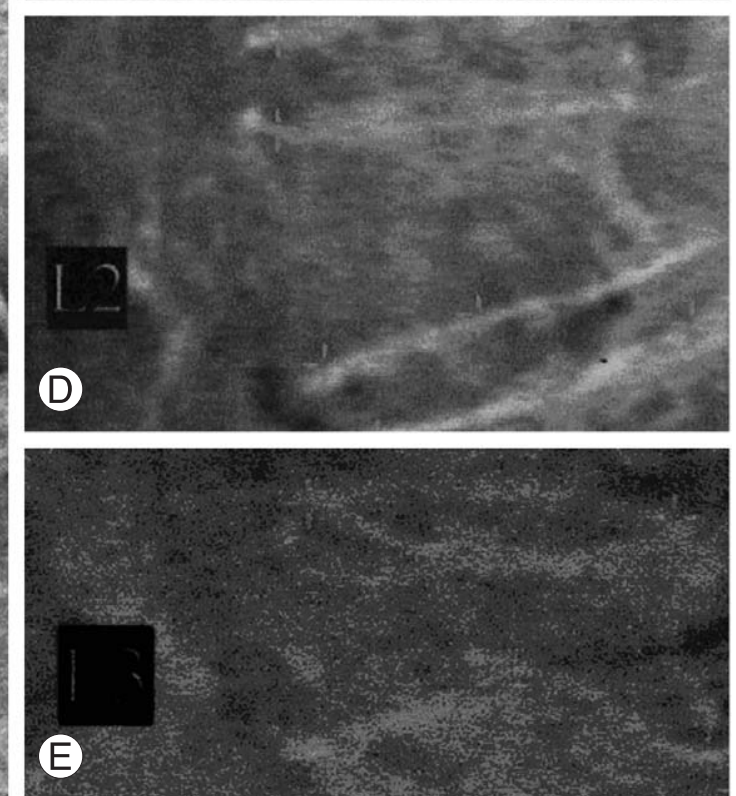

Fig. 2. LVA-DXA scans of the patients. (A) One LVA-DXA scan from T4 to L4. (B) Normal vertebral body of T10. (C) A Grade 1 wedge VF at T11 (24\% loss of vertebral height). (D) A Grade 2 wedge VF at L2 (29\% loss of vertebral height). (E) A Grade 3 biconcave VF at L3 (46\% loss of vertebral height). LVA: Lateral vertebral assessment, DXA: Dual-energy X-ray absorptiometry, VF: Vertebral fracture. 
by O'Neill et al. [24], $19 \%$ in the study by Kanterewicz et al. [25] and 25\% in the study by Gallacher et al. [23].

Vertebral fractures (single and multiple) were detected in $21.7 \%$ (of which $40 \%$ were multiple) of the patients in the normal lumbar T-score group in this study. This was higher than that of similar studies: $18.7 \%$ in O'Neill et al.'s study [24] and $16 \%$ in Gallacher et al.'s study [23]. So, this is important to note that many of patients presenting with back pain may have VF even with a normal BMD.

Obviously VFs are much less common in patients with a normal T-score (22\% [10/46]) as compared to VFs in those patients with osteopenia (37.5\% [36/96]) and osteoporosis (43.6\% [88/202]), but among the patients with VFs, a single VF was seen in about $60 \%$ in the patients with normal Tscore $(60 \%$ [6/10]) and osteopenia (61\% [22/36]), while only $25 \%$ of the osteoporotic patients (22/88) had a single VF.

In contrast, multiple fractures were more commonly seen in the patients with osteoporosis (75\% [66/88]) and multiple fractures were less common in patients with a normal Tscore $(40 \%$ [4/10]) and osteopenia $(39 \%$ [14/36]). As a result, if a patient with osteoporosis is detected to have a VF, then we can expect them to have multiple VF rather than a single VF and so other fractures might be missed in a patient with osteoporosis if enough care is not paid when assessing for vertebral fractures.

Likewise, similar findings can be seen in patients with a lower BMI. Underweight patients (BMI, $<20 \mathrm{~kg} / \mathrm{m}^{2}$ ) were at a higher risk for VFs as compared to other subgroups $(p=$ 0.008) (Table 1).

Although this study did not assess the risk factors of osteoporosis, it seems that age is the most weighted risk factor for osteoporosis. The prevalence and severity of VFs were significantly increased with aging $(p=0.001)$ (Table 1). Furthermore, the mean age of patients with VFs was higher $(62.75 \pm 10.94$ years) than that of the patients without VFs (55.31 \pm 11.33 years).

Additionally, lumbar VFs were seen only in $52 \%$ of the patients (whether isolated in the lumbar [25\%] or associated with thoracic VFs [27\%]), while in the same manner, 75\% of VFs were detected in the thoracic spine (48\% isolated thoracic VFs and 27\% in the thoracic and lumbar spine). Therefore, in our study the thoracic VFs were more common relative to that of the lumbar VFs. These findings were comparable to the findings of similar studies [23].

\section{Conclusions}

While BMD is widely used in the evaluation of the patients, radiological assessment of vertebral fractures is commonly not performed, or if it is performed, the tests and results are inadequately standardized and interpreted. In our study, there was a high prevalence of osteoporosis and undiagnosed VF in elder patients (over 50 years old) ith back pain, so we recommend additional LVA using classic DXA for the assessment of VFs and this may become a standard diagnostic method for patients presenting with back pain and who are clinically suspicious for VF.

Our study clearly showed that single VFs were more common in patients with a normal T-score and osteopenia while multiple VFs are more commonly seen in osteoporotic patients. Thus, careful investigation for multiple foci of fractures should be done in osteoporotic patients.

\section{Acknowledgements}

This study was supported by Sina Medical Imaging Center, Birjand, Iran. We thank Ms S. Saadet, Ms F. Amadi, Ms S. Hosainaee and Ms S. Abbasi for their kind cooperation. We also wish to thank the Farzan Institute for Research and Technology for the technical assistance.

\section{REFERENCES}

1. Cooper C, O'Neill T, Silman A. The epidemiology of vertebral fractures. European Vertebral Osteoporosis Study Group. Bone 1993;14 Suppl 1:S89-97.

2. Klotzbuecher CM, Ross PD, Landsman PB, Abbott TA 3rd, Berger M. Patients with prior fractures have an increased risk of future fractures: a summary of the literature and statistical synthesis. J Bone Miner Res 2000;15: 721-39.

3. Kanis JA, Johnell O, De Laet C, et al. A meta-analysis of previous fracture and subsequent fracture risk. Bone 2004;35:375-82.

4. Black DM, Arden NK, Palermo L, Pearson J, Cummings SR. Prevalent vertebral deformities predict hip fractures and new vertebral deformities but not wrist fractures. Study of Osteoporotic Fractures Research Group. J Bone Miner Res 1999;14:821-8.

5. Pongchaiyakul C, Nguyen ND, Jones G, Center JR, Eisman JA, Nguyen TV. Asymptomatic vertebral deformity as a 
major risk factor for subsequent fractures and mortality: a long-term prospective study. J Bone Miner Res 2005;20: 1349-55.

6. Scane AC, Sutcliffe AM, Francis RM. The sequelae of vertebral crush fractures in men. Osteoporos Int 1994;4:89-92.

7. Ferrar L, Jiang G, Adams J, Eastell R. Identification of vertebral fractures: an update. Osteoporos Int 2005;16:717-28.

8. Vokes T, Bachman D, Baim S, et al. Vertebral fracture assessment: the 2005 ISCD Official Positions. J Clin Densitom 2006;9:37-46.

9. Genant HK, Jergas M, Palermo L, et al. Comparison of semiquantitative visual and quantitative morphometric assessment of prevalent and incident vertebral fractures in osteoporosis The Study of Osteoporotic Fractures Research Group. J Bone Miner Res 1996;11:984-96.

10. Jergas M, Lang TF, Fuerst T. Morphometric X-ray absorptiometry. In: Genant HK, Jergas M, van Kuijk C, editors. Vertebral fracture in osteoporosis. San Francisco: Radiology Research and Education Foundation Publishers; 1995. p. 331-48.

11. Hans D, Baiada A, Duboeuf F, Vignot E, Bochu M, Meunier PJ. Expert-XL: clinical evaluation of a new morphometric technique on 21 patients with vertebral fracture. Osteoporos Int 1996;6:79.

12. Blake GM, Rea JA, Fogelman I. Vertebral morphometry studies using dual-energy $x$-ray absorptiometry. Semin Nucl Med 1997;27:276-90.

13. Lang T, Takada M, Gee R, et al. A preliminary evaluation of the lunar expert-XL for bone densitometry and vertebral morphometry. J Bone Miner Res 1997;12:136-43.

14. Rea JA, Steiger P, Blake GM, Fogelman I. Optimizing data acquisition and analysis of morphometric X-ray absorptiometry. Osteoporos Int 1998;8:177-83.

15. Rea JA, Li J, Blake GM, Steiger P, Genant HK, Fogelman I. Visual assessment of vertebral deformity by X-ray absorptiometry: a highly predictive method to exclude vertebral deformity. Osteoporos Int 2000;11:660-8.

16. Ferrar L, Jiang G, Eastell R, Peel NF. Visual identification of vertebral fractures in osteoporosis using morphometric X-ray absorptiometry. J Bone Miner Res 2003;18:933-8.

17. Baim S, Wilson CR, Lewiecki EM, Luckey MM, Downs RW Jr, Lentle BC. Precision assessment and radiation safety for dual-energy X-ray absorptiometry: position paper of the International Society for Clinical Densitometry. J Clin Densitom 2005;8:371-8.

18. Grigoryan M, Guermazi A, Roemer FW, Delmas PD, Genant HK. Recognizing and reporting osteoporotic vertebral fractures. Eur Spine J 2003;12 Suppl 2:S104-12.

19. Binkley N, Krueger D, Gangnon R, Genant HK, Drezner MK. Lateral vertebral assessment: a valuable technique to detect clinically significant vertebral fractures. Osteoporos Int 2005;16:1513-8.

20. Vokes TJ, Dixon LB, Favus MJ. Clinical utility of dualenergy vertebral assessment (DVA). Osteoporos Int 2003;14:871-8.

21. Abdel-Hamid Osman A, Bassiouni H, Koutri R, Nijs J, Geusens P, Dequeker J. Aging of the thoracic spine: distinction between wedging in osteoarthritis and fracture in osteoporosis. A cross-sectional and longitudinal study. Bone 1994; 15:437-42.

22. Delmas PD, Watts N, Eastell R, von Ingersleben G, van de Langerijt L, Cahall DL. Underdiagnosis of vertebral fractures is a worldwide problem: The IMPACT Study. J Bone Miner Res 2001;16 Suppl 1:S139.

23. Gallacher SJ, Gallagher AP, McQuillian C, Mitchell PJ, Dixon T. The prevalence of vertebral fracture amongst patients presenting with non-vertebral fractures. Osteoporos Int 2007; 18:185-92.

24. O'Neill TW, Cockerill W, Matthis C, et al. Back pain, disability, and radiographic vertebral fracture in European women: a prospective study. Osteoporos Int 2004;15:7605.

25. Kanterewicz E, Yañez A, Del Rio L, Diez Pérez A, Carbonell J. Vertebral morphometric X-ray absorptiometry in women with Colles' fracture. J Clin Densitom 2003;6:35966. 